\title{
Comparative analysis of students and faculty level of awareness and knowledge of digital citizenship practices in a distance learning environment: case study
}

\author{
Mahmoud Hawamdeh $^{1}$ (D) Zehra Altınay $^{1} \cdot$ Fahriye Altınay $^{1} \cdot$ Ahmet Arnavut $^{2}$. \\ Kezban Ozansoy ${ }^{1} \cdot$ Idris Adamu $^{1}$
}

Received: 24 July 2021 / Accepted: 14 December 2021 / Published online: 28 January 2022

(c) The Author(s), under exclusive licence to Springer Science+Business Media, LLC, part of Springer Nature 2021

\begin{abstract}
The COVID-19 pandemic increase the use of distance learning while studies have shown that there is insufficient digital knowledge among students in distance leaning as they do not adequately use technology as a digital citizenship indicator, while the awareness and knowledge of digital citizenship among teachers and students remains a key criterion for improving distance learning that mainly depends on information technology. Therefore, this study comes up to examine the awareness and knowledge of students and faculty of digital citizenship in distance environment by focusing on two different higher academic institutions, namely the Al-Quds Open University (QOU) in the Palestinian territories and the University of Kyrenia (KU) in the Turkish Republic of Northern Cyprus in 2020, using interview, descriptive analysis, and Z-test Technique. The results revealed that students and faculty in both institutions were aware of the digital citizenship concepts, but lacked the in-depth knowledge and understanding of concepts such as digital rights, digital security, and digital ethics. Furthermore, the awareness and knowledge of digital citizenship among KU students are higher than QOU students. Faculty in both institutions agreed with the importance of integrating digital citizenship practices such as digital rights, digital security, and digital ethics into elearning curriculum.
\end{abstract}

Keywords Digital citizenship · Distance learning · e-learning · ICT · Comparative study

Mahmoud Hawamdeh

mhawamdeh@qou.edu

1 Near East University, Nicosia, Cyprus

2 University of Kyrenia, Kyrenia, Cyprus 


\section{Introduction}

Nowadays, there are advancements in technology and education alike with the introduction of various strategies and techniques for educators and learners to increase their knowledge. Almarashdeh and Alsmadi (2016) reviewed the Learning Management System (LMS) for facilitating distance learning programs. The LMS has a critical role in the play. It channels the interaction between learners and instructors and is a kind of a platform in universities to bridge learners' needs to the curriculum requirements; thus, the LMS serves as an interactive medium between students and instructors. Furthermore, the LMS is one of the examples of positive engagement of students with digital technologies, which is highly crucial nowadays where e-learning and distance learning are becoming the driving means for impacting learning in a digital environment. As we become active users and participants of a digital environment, we become entitled to the benefits and privileges of the digital world offer, but there is an obligation to the users and participant to be digital citizenship. The term digital citizenship is a teaching solution proposed by Ribble and Bailey (2007) where proper technology behavior is taught. Since then, various scholars have defined the concept of digital citizenship almost tallied with one another when it came to the concept of digital citizenship. Digital citizenship, according to Snyder (2016), is the ethical, moral, and responsible use of technology to ensure one's own and others' protection while collaborating in an increasingly digital, networked, and global society. Moreover, Snyder includes relevant and pressing need for networked communications via social media, reaping positive outcomes related to education in global settings. Following Zook (2019), anyone who uses computers, the Internet, or digital devices to communicate with society at any level is referred to as having digital citizenship. This is why, for today's students, digital citizenship is such an important subject, particularly those on e-learning and distance learning.

As per the study of Ata and Y1ldırım (2019), digital citizenship has been based on positive engagement with digital technologies, including sharing, investigating, learning, and communicating. Clough and Closier (2018) article discusses the approaches that the Open University (UK) library has taken to ascertain that distance learning students must acquire all the necessary digital skills for studying at the university to work as a professional and to commit themselves to lifelong learning. This perception by the Open University library is an indicator of a holistic view expressing the direction taken by the developed country's university management to ensure their students achieve digital citizenship. Moreover, in the wake of the COVID-19 pandemic, government agencies, NGOs, and civil society are occupied with the urgent need to deliver education remotely through a technological mix to ensure continuity of study (based on curriculum guidelines) and learning (UNESCO, 2020). In the words of Maftuhin et al. (2021), the Covid19 epidemic, which erupted in numerous parts of the world, has had an impact on various aspects of society, including schooling. With the Covid-19 epidemic, learning that was previously only done in person must now be done online. However, the key challenging issue is that there is insufficient digital knowledge 
among students. They do not adequately use technology as a digital citizenship indicator, while the awareness and knowledge of digital citizenship among teachers and students remains a key criterion for improving distance learning that mainly depends on information technology (Jwaifell \& Alkhales, 2019). More so, there is inadequate understanding and knowledge of digital law and digital safety among students and teachers (Suson, 2019). These are some of the latest findings on the ground.

But how does the situation look with the eruption of the Covid-19 pandemic? Also, is there a difference in the awareness and knowledge of students and faculty members in a distance learning environment of different countries of the same class? Given the fact that digital citizenship is a new area and the fact that there are limited number of studies about ethical issues and responsible use of technology. The proposed study fills a gap in the literature about digital citizenship especially comparative studies between different higher academic institutions in developing countries. This study examines and compares the awareness and knowledge of faculty and students of digital citizenship and responsible use of technology in two online universities, namely Al-Quds Open University (QOU) in Palestine and University of Kyrenia (KU) in the Turkish Republic of Northern Cyprus (Tables 1 and 2).

The study is comparative and its scope covers two higher institutions involve in distance learning, namely the Al-Quds Open University (QOU) in the Palestinian territories and the University of Kyrenia (KU) in the Turkish Republic of Northern Cyprus. In research involving primary data in which some part (as in this study) or whole will be collected through interview, it will be more suitable to conduct the

Table 1 Characteristics of Al-Quds Open University (QOU) and University of Kyrenia (KU)

\begin{tabular}{|c|c|}
\hline Al-Quds Open University & University of Kyrenia \\
\hline $\begin{array}{l}\text { - QOU is located in a developing country } \\
\text { - Is an administratively, academically and finan- } \\
\text { cially independent public university } \\
\text { - It was established in Amman by a decree issued } \\
\text { by the Palestinian Liberation Organization (PLO) } \\
\text { and started operating in Palestinian territories } \\
\text { in } 1991 \\
\text { - QOU has no international students } \\
\text { - QOU has distance learning center offering dis- } \\
\text { tance learning courses } \\
\text { - It is considered the largest university that has } \\
\text { over } 60,000 \text { students studying in } 24 \text { educational } \\
\text { regions and centers distributed all over the West } \\
\text { Bank and Gaza Strip } \\
\text { - Highest Degree is Bachelor } \\
\text { - The university has } 5 \text { faculties leading to BA } \\
\text { Degree as follows: Technology and Applied Sci- } \\
\text { ences, Agriculture Program, Social and Family } \\
\text { Development, Administrative and Economic } \\
\text { Sciences, and Education Program } \\
\text { - The language used is Arabic and English } \\
\text { - Student: staff ratio is } 10: 1\end{array}$ & $\begin{array}{l}\text { - KU is located in a developing country } \\
\text { - Girne Üniversitesi (University of Kyrenia) is a } \\
\text { non-profit private higher-education institution } \\
\text { - University of Kyrenia founded in } 2013 \text { and is } \\
\text { recognized by the Higher Education Council } \\
\text { of Turkey (YOK) and approved by the TRNC's } \\
\text { Ministry of National Education } \\
\text { - KU has international students } \\
\text { - KU has distance learning center offering distance } \\
\text { learning courses } \\
\text { - University of Kyrenia (UoK) is one of the fastest } \\
\text { growing universities in Cyprus and one of the } \\
\text { most prominent educational institutions in the } \\
\text { region, providing education } \\
\text { - Highest Degree is Master } \\
\text { - There are } 12 \text { faculties, } 3 \text { vocational schools, } 3 \\
\text { graduate schools and an academy, in total } 58 \\
\text { programs } \\
\text { - The language used is Turkish and English } \\
\text { - Student: staff ratio is } 10: 1\end{array}$ \\
\hline
\end{tabular}


Table 2 Differences and similarities of Al-Quds Open University (QOU) and University of Kyrenia (KU)

\begin{tabular}{|c|c|}
\hline Differences in QOU and KU & Similarities in QOU and KU \\
\hline $\begin{array}{l}\text { - KU offers more courses than QOU } \\
\text { - KU has international students while QOU just has } \\
\text { Palestinian students } \\
\text { - There are more students in QOU than in KU } \\
\text { - There are more faculties and courses in KU than } \\
\text { in QOU }\end{array}$ & $\begin{array}{l}\text { - Both universities are located in developing } \\
\text { countries } \\
\text { - Both universities offer up to a master degree } \\
\text { - Both universities are not profit oriented objective } \\
\text { but public service } \\
\text { - Both universities have distance learning center } \\
\text { offering distance learning courses } \\
\text { - In both universities English is used in providing } \\
\text { education } \\
\text { - In both universities the students staff ratio is 10:1 }\end{array}$ \\
\hline
\end{tabular}

Source: Authors' compilation

research in the area you are familiar with. Also, in comparison, it will be interesting to compare things that have certain features in common. These are the reasons that make this study to choose those universities. However, the specific objectives of this study are:

i. To examine the levels of awareness and knowledge of students and faculty members on digital citizenship in a distance learning environment in both AlQuds Open University in Palestine and the University of Kyrenia in the Turkish Republic of Northern Cyprus; and

ii. To assess students and faculty recognition and perception of the importance of digital citizenship and ethical use of technology in distant learning education and the importance of integrating digital citizenship in the curriculum.

The importance of this study to policymkaers could be seen based on answers to the questions relating to the facts that before the advent of COVID-19 pandemic, there is insufficient digital knowledge among students and faculty. But how does the situation look with the eruption of the Covid-19 pandemic? Also, is there a difference in the awareness and knowledge of students and faculty members in a distance learning environment of different countries of the same class? Furthermore, the findings of this study are expected to be useful enhance the digital citizenship skills for distance learning and integrated that in distance learning curriculum.

The organization of the rest of the paper went as follows: literature review comprising both theoretical and empirical reviews, methodology, results, discussions, and concluding remarks of the paper.

\section{Literature review}

\subsection{Theoretical review}

The epoch in which we live is known and referred to as the digital age of technology, where technology is changing and developing rapidly in this age. In light of 
these technological advances in this twenty-first century, schools must train "digital citizens" as well as good citizens. Digital citizens must have extensive skills and knowledge, and access to the Internet and technology, and schools must guide students in becoming digital citizens. Manasco (2020) added that as students are currently taking classes online due to the COVID-19 pandemic, it's important that they know how to be responsible digital citizens. However, the teachers/educators too need to promote digital citizenship through distance learning and this can be achieved by holding online discussions about digital citizenship and distance learning, encouraging activities outside of social media, share video resources, including digital citizenship in online learning assignments, and have students write it out i.e. after these lessons or a day of limited social media use, ask students to journal their thoughts. Some characteristics of a digital citizen include understanding human, cultural, and societal issues related to technology and practising legal and ethical behavior; advocating for and practicing safe, legal, and responsible use of information and technology; demonstrate a positive attitude toward using technology to support collaboration, learning, and productivity; demonstrate personal responsibility for lifelong learning; and demonstrate digital citizenship leadership (Isman \& Gungoren, 2014; Ribble, 2008). Furthermore, digital citizenship should not be a laundry list of dos and don'ts. It should be about the actions that contribute to the development of thoughtful, empathetic digital citizens capable of grappling with the important ethical questions at the intersection of technology and humanity. Among these dos are using technology to improve your community, engaging respectfully online with people who hold different beliefs than you, using technology to make your voice heard by public officials and influence public policy, as well as determining the veracity of online information sources. Conversations about personal responsibility are not the only topics covered by digital citizenship. It is about being active citizens who see opportunities rather than problems, and as they cultivate a positive and effective digital footprint, they see opportunities rather than risks. However, Pedersen et al. (2018) presented a technical innovation in education by introducing the concept of hybrid education in digital citizenship. The hybrid concept of education was defined as an on-site and online learning model, increasing digital citizenship awareness as well as bridging the gaps of distance learning. They conducted workshops and training on the effectiveness of the hybrid model and concluded that the model was successful in strengthening the gaps that were part of the digital citizenship and distance learning platform. In addition, Fields and Hartnett (2018) discussed the concept of digital fluency in the distance learning model. The editorial covered the aspects of distance and flexible learning combinations in the current education system. It concluded that with the current times, the students employ all the tools at their disposal, whether distance-learning or face-to-face, thus creating a concept of flexible learning that creates wider knowledge and clears the boundaries of education.

Notwithstanding, the goals of digital citizenship in the twenty-first century are to educate, empower, and protect (Common Sense Media White Paper, 2011). Ribble and Bailey (2007) explained these three as respect (etiquette, access, law), educate (communication, literacy, commerce), and protect (rights and responsibility, safety/ security, health and welfare), according to Ribble and Bailey (2007) and Isman and 
Gungoren (2014). As digital citizens are becoming increasingly important in today's world, some key features in education can help students become digital citizens to achieve the 21st-century digital citizenship goals. These key factors include student learning and academic performance, student environment and behavior, and student life outside school. Ribble and Bailey (2007) classified the nine areas of behavior that comprise digital citizenship into three categories as in Table 3.

Student Learning \& Academic Performance

1- Digital Access: full electronic participation in society.

2- Digital Communication: electronic exchange of information.

3- Digital Literacy: the process of teaching and learning about technology and the use of technology.

\section{Student Environment \& Student Behavior}

4- Digital Security (self-protection): electronic precautions to guarantee safety.

5- Digital Etiquette: electronic standards of conduct or procedure.

6- Digital Rights \& Responsibilities: those freedoms extended to everyone in the digital world.

\section{Student Life outside the School Environment}

7- Digital Law: electronic responsibility for actions and deeds

8- Digital Health \& Wellness: physical and psychological well-being in a digital technology world.

9- Digital Commerce: electronic buying and selling of goods.

\subsection{Empirical review}

In the literature, various empirical studies have been conducted, including Jwaifell and Alkhales (2019), who compare the appropriate use of technology as an indicator of digital citizenship in two different universities in Jordan and Palestine. Digital citizenship is defined in terms of nine elements, including etiquette, communication, and access; the study results indicate a lack of knowledge because they do not adequately use technology as a digital citizenship indicator. Xu et al. (2019) examined social media competence (SMC) regarding digital citizenship amongst students. 722 college students

Table 3 Digital citizenship touchpoints

\begin{tabular}{|c|c|c|}
\hline $\begin{array}{l}\text { (1) Student learning and } \\
\text { academic performance }\end{array}$ & (2) Student environment and behavior & (3) Student life outside of school \\
\hline i. Digital Access & i. Digital security and safety & i. Digital law \\
\hline $\begin{array}{l}\text { ii. Digital Communication } \\
\text { iii. Digital Literacy }\end{array}$ & $\begin{array}{l}\text { ii. Digital Etiquette } \\
\text { iii. Digital rights and responsibilities }\end{array}$ & $\begin{array}{l}\text { ii. Digital health and wellness } \\
\text { iii. Digital commerce }\end{array}$ \\
\hline
\end{tabular}

Source: Researchers' Compilation 
were selected for the study and evaluated their social media competencies on their digital citizenship. The research concluded that out of six competency criteria examined, five predictors of an individual's digital citizenship. The findings identified a relationship between the SMC and the digital citizenship of students, and these competency criteria must be kept in mind by the teachers when formalizing educational programs and designing curricula for improving digital citizenship. Suson (2019) employed the model of Ribble and Bailey for digital citizenship in schools in the Philippines. The research was based on the awareness of teachers and students on the concept of digital citizenship in a select sample study area. The study concluded that the students and teachers alike were moderately aware of digital citizenship in schools and that even though many are aware of the concept, there is still a lack of digital law and digital safety that leads to a high-risk factor. Al-Abdullatif and Gameil (2020) conducted a study concerning the students' experience and perceptions of digital citizenship. The population was assessed on their knowledge and experience of eight of the nine elements of digital citizenship. The analysis included 204 undergraduate students who were chosen by purposeful sampling. The study concluded that even though many of the students are aware of digital citizenship, there is a wide gap in knowledge and practice regarding the security and authenticity of information amongst students. It showed that the usage of the Internet does not increase the digital citizenship of an individual if it is not utilized properly; however, the nature of academic specializations and knowledge do contribute to the digital knowledge of an individual. Elmali et al. (2020) determined the perceptions of pre-school teachers regarding digital citizenship and their level of digital citizenship. The study consisted of 80 teaching candidates, employing quantitative and qualitative methods, employing surveys and interviews to understand the participants' perceptions better. It was concluded from the study that the perceptions of digital citizenship of the participants were above average; however, a lacking was in the form of digital rights and responsibilities as well as digital security. Grammon (2020) conducts a comparative study on comparing digital citizenship perceptions of online students and teachers from the same population using the DCS (Digital Citizenship Scale) instrument created by Choi et al. (2017) and make use of t-test technique based on a sample size consisting of 114 students and 93 teachers from an online Oregon school where the results indicated no statistically significant difference in digital citizenship perceptions between online, secondary students and teachers. The research conducted by Martin et al. (2020) considers middle school students' perception as it relates to their digital citizenship practices. The study results indicate that mobile devices' use among students has increased; therefore, the parents bear the responsibility to check their children's online behavior, and $37.1 \%$ of the students revealed that their schools had taught them about digital citizenship. The study concludes that students lack a basic understanding of digital citizenship, which has broad consequences for teachers, administrators, and parents. 


\section{Methodology}

\subsection{Participants and sampling}

The study participants were selected from two different higher academic institutions with a diverse population of students using a sample size formula based on standard 5\% margin error procedure, namely Al-Quds Open University (QOU) in the Palestinian territories and the University of Kyrenia (KU) in the Turkish Republic of Northern Cyprus. The research covered both qualitative and quantitative study.

For the qualitative part of the study, the research employed a non-probability sampling technique. Instead of random sampling, the research chose samples based on its subjective judgment on this method. It is a less stringent method, but it allows the researcher to use his knowledge and expertise in selecting the sample (Strauss \& Corbin, 1990). Specifically, the non-probability sampling technique employed to select the faculty members for the interview is the purposive sampling technique. Under this sampling technique, the research used its judgment for the sample based on the research questions. The purposive sampling technique depends on the researcher's judgment so as to effectively collect data from the experienced relevant teachers and students. In the data collection, an online interview technique through ZOOM was used due to the current situation of the COVID-19 pandemic. The Zoom connection is the current preferred method for the qualitative research approach.

The researcher interviews 16 faculty members in total, 8 from the faculty of the Al-Quds Open University (QOU) in which two of them were females and six of them were males. Three of them in Technology and Applied Science faculty, two in the Educational Science faculty, one in English Department and One in the media and one ICT as shown in Table 4; and 8 from the faculty of the University of Kyrenia $(\mathrm{KU})$ in which two of them were females and six of them were males. Five of them are related to Computer Education and Institutional Faculty, one participant work in English department, another in preparatory school, and one in special education teaching as shown in Table 5.

While for the quantitative part of the study, an online survey was employed to provide a complete understanding of the student's awareness and knowledge on

Table 4 Demographic data of the interviewed faculty members in Al-Quds Open University

\begin{tabular}{|c|c|c|}
\hline Participant No & Gender & Major \\
\hline 1 & Female & Faculty member of Education Science Faculty \\
\hline 2 & Male & $\begin{array}{l}\text { Head of ICT Research Unit and Faculty member in Technol- } \\
\text { ogy and Applied Science faculty }\end{array}$ \\
\hline 3 & Male & Faculty member in Technology and Applied Science Faculty \\
\hline 4 & Male & Faculty member in English Department \\
\hline 5 & Male & Dean of Media Faculty \\
\hline 6 & Male & Faculty member /Technology and Applied Science Faculty \\
\hline 7 & Male & Faculty member/Educational Science Faculty \\
\hline 8 & Female & Faculty member/Technology and Applied Science Faculty \\
\hline
\end{tabular}


Table 5 Demographic data of the interviewed faculty members in University of Kyrenia

\begin{tabular}{lll}
\hline Participant No & Gender & Major \\
\hline 1 & Male & Computer Education and Instructional Technology \\
2 & Male & Department of English Teaching \\
3 & Female & Head of Preparatory School \\
4 & Male & Doctorate Student/Computer Education and Instructional Technology \\
5 & Male & Doctorate Student/Computer Education and Instructional Technology \\
6 & Male & Computer Education and Instructional Technology \\
7 & Female & Head of Special Education Teaching \\
8 & Male & Computer Education and Instructional Technology \\
\hline
\end{tabular}

Source: Researchers' Compilation

digital citizenship in a distance learning environment. The survey constituted 812 students, of which 557 from the Al-Quds Open University (QOU) and 255 from the University of Kyrenia (KU) where the selection of the students executed using a simple random sampling technique in which each student had an equal chance of being selected from a total of 2,500 in the Al-Quds Open University (QOU) and 44,305 from the University of Kyrenia (KU). Nonetheless, the sample gender is based on sex ratio of the respondents available in the named higher institutions.

\subsection{Structured surveys and interviews on the digital citizenship}

With respect to the faculty members, the concept of digital citizenship was evaluated through structured interviews conducted with the faculty. The interview consisted of 11 queries designed to assess the faculty members' level of awareness and knowledge. The researcher conducts the interviews to explore the perceptions of the faculty as it relates to knowledge and awareness of digital citizenship in a distance learning environment. For achieving reliability and validity, the interviews were designed to ensure that the researcher will get the same responses from participants in the two higher academic institutions. The interviews were conducted in English and the questions were asked in the same way. Once the approval for the interviews was received from both institutions' administration, an email was sent to the faculty participants at both universities, and interviews were scheduled. A brief discussion on the purpose of the study was conducted with each of the participants at the beginning of the interview, where the researcher used the Digital Citizenship Scale (DCS) to collect the quantitative data after he received approval from the DCS scales Authors. Choi et al. (2017) developed the DCS from Ohio State University in the USA. The DCS scale is a five-factor model derived using an Exploratory Factor Analysis (EFA). According to Choi et al. (2017), "The DCS had respected strong reliability and positive evidence, supported by concept analysis of the digital citizenship, the review panel, the EFA, and the CFA" "P100". On the other hand, the researcher adopted some of the relevant questions and assessed the student's awareness and knowledge of digital citizenship. The survey questions used 5 points 
Likert-type scale where agreement/disagreement was marked as Strongly disagree, Disagree, Neutral, Agree, and Strongly agree.

For the qualitative part of the study with the faculty, once the data collection is completed, the researchers embarked on transcribing the interview transcripts in a manner that made it possible for themes to be identifiable from the interview. This process started with a thorough reading of the interview transcripts several times to understand major issues pointed with respect to digital citizenship knowledge and students' awareness based on their teachers' perceptions. During the reading process, the researcher noted some notes and created a summary of the interview transcripts. Through the analysis, the coding technique is used to highlight the main meanings and ideas, grouping similar gathered information in categories, then relate the constructed data to the main research themes. The whole process of transcribing the interview responses was accomplished manually without any specific analytical software.

Nonetheless, the survey data collected from the students were analyzed using Statistical Package for Social Sciences (SPSS) version 20. After getting the data from the survey conducted through Google form, analyzing the data started by cleaning it first. The data was checked for any inadequacies like missing variables, unfilled spaces, and during that, data was also considered to be useful or not. Data were coded and entered into the SPSS, and then the analysis thereof kicked off.

\section{Research methods}

A mixed-method approach integrating qualitative and quantitative data collection and analysis was used in this paper. The study was conducted et al.-Quds Open University (QOU) in Palestine and The University of Kyrenia (KU) in the Turkish Republic of Northern Cyprus during the fall semester of the year 2020. The selected universities used distance learning technologies to deliver learning courses. However, as a case study method, the research carried based on the research experience and teachers' opinions on students' evolution and students' experiences as digital citizens in distance learning, and to draw a comparison between the two universities.

To statistically determine the level of awareness and knowledge of students on digital citizenship in a distance learning environment among the two higher institutions, and whether there is significance difference of students' awareness and knowledge on digital citizenship in distance learning environment between the two higher institutions, the paper will employ Z-test Technique for Different in Proportion which is the test for determining whether two proportions differ significantly. For students' awareness, it will be employed based on the students' responses from the following questions - to what extent digital citizenship brings positive social change, digital citizenship promotes ethical and moral use of technology, students' awareness of their health, and students belonging to an online community related to social or political issues. However, for students' knowledge, it will be employed based on the students' responses from the following questions - prior knowledge of digital citizenship, engaging in bullying behaviour in an online environment, deleting emails from suspicious 
senders, and digital citizenship promotes cybersecurity social responsibility. Furthermore, the questions on both the awareness and knowledge will have three options as follows: strongly agreed, agreed, neutral, strongly disagreed, and disagreed. For the test set, strongly agreed and agreed will be merged as the same (i.e., the proportion of positive responses) while strongly disagreed and disagreed will be merged as the same (i.e., the proportion of the negative responses). Moreover, the calculated $Z$-score will be compared with the tabulated $Z$-scores at $1 \%, 5 \%$, and $10 \%$ levels of significance where the respected tabulated $Z$-scores are between -2.54 to $2.54,-1.96$ to 1.96 , and -1.645 to 1.645 , i.e. at $1 \%, 5 \%$, and $10 \%$, respectively.

On the other hand, the faculty awareness and knowledge on digital citizenship in a distance learning environment is based on an open question that is purely qualitative and therefore, no assigned options but just a verbal response being the most suitable way to tap the required information from the rich knowledge of the faculty members. However, the faculty awareness of digital citizenship will be based on open responses regarding the importance of digital citizenship, whether students are equipped to engage responsibly in digital citizenship, and the differences between students' digital citizenship practice according to sex, age, and study level. At the same time, the faculty knowledge of digital citizenship will be based on open responses with regard to the teaching of digital citizenship through distance learning, integration of digital citizenship into the distance learning curriculum, available resources and tools to incorporate in digital citizenship, and Changes Needed in Curricula for Digital Citizenship.

\section{Results}

\subsection{Demographic characteristics of the respondents}

The data was collected from two different higher academic institutions - the AlQuds Open University (QU) in the Palestinian territories and the University of Kyrenia (KU) in the Turkish Republic of Northern Cyprus. The total number of enrolled students was 812 where 557 are from the Al-Quds Open University (QOU)and 225 are from the University of Kyrenia (KU). The sample consists of $(549,67.6 \%)$ females and $(263,32.4 \%)$ males; the enrolled sample was varied in age groups, $(561,69.1 \%)$ out of the total students were between 18-22 years old, while $(127,15.6 \%)$ were more than 26 years old, the remaining of the sample (124, 15.3\%) belonged to age group 23-25 years old. However, regarding the study level of the sample, the majority of the respondents were in the first and fourth year of study $(361,44.5 \%)$ and $(243,29.9 \%)$, respectively. While only $(90,11.1 \%)$ and $(118,14.5 \%)$ were in the second and third year of study, respectively. The number of students selected for each level was drawn based on strata for each level in the respective universities. 


\subsection{The AI-Quds Open University (QOU) students' responses}

The students' responses from the Al-Quds Open University (QOU) show that 557 students from the Al-Quds Open University (QOU) answered the 25 questions (418, $75.0 \%)$ females and $(139,25.0 \%)$ males. This can be attributed to the fact that most students in Al-Quds Open University (QOU) are females. Hence, when the study was conducted, it became normal to get many respondents from a female. The enrolled sample was varied in age groups, $(353,63.4 \%)$ out of the participants from Al-Quds Open University (QOU) were between 18-22 years old, while $(108,19.4 \%)$ were more than 26 years old, the remaining of the sample $(96,17.2 \%)$ belonged to age group 23-25 years old. However, regarding the study level of the sample, out of the enrolled sample, $(120,21.5 \%)$ were in the first year of study, and $(82,14.7 \%)$ were in the second year of study. While $(114,20.5 \%)$ and $(241,43.3 \%)$ were in the third and fourth year of study.

Tables 6 and 7 shows the students response with respect to the 25 research questions in which the values outside the brackets are the number of students in each case, the values in parenthesis is percentages/proportions, while the boldness symbolized the majority. From the table, majority of the students strongly agreed that they do not engage in bullying behavior in an online environment. For all the remaining twentyfour research questions, the students agreed that they do respect other people in the online environment; responsible for their own online activities; using the internet to access more information about domestic and international issues; aware of the order of others in the online environment; obeying the order in the environment; using digital technology to achieve various goals; immediately manage unnecessary files and programs on their computers; expressing their opinions online and learn and share their expertise; purchasing legitimate goods during e-commerce activities; aware of my health problems caused by the abuse of digital devices such as addiction and stress; establishing their beliefs and values about the digital environment; immediately deleting emails from suspicious senders; presenting their feelings, thoughts, and opinions while posting text, photos, music, or videos online; always check the price on the Internet when purchasing goods; work with others online to solve social or my university problems; active in social network services such as Facebook and Twitter; having prior knowledge that digital citizenship is to engage in appropriate and responsible behavior when using technology; digital citizenship brings positive social change; digital citizenship promotes ethical and moral use of technology in distance learning; digital citizenship promotes cyber-security and social responsibility in distance learning; instruction in digital citizenship should be included in existing distance learning curricula; purchasing legitimate goods during e-commerce activities, belonging to an online community related to social or political issues, and taking care of the computer immediately if something goes wrong.

\subsection{The University of Kyrenia (UK) students' responses}

The students' responses from the University of Kyrenia (KU) show that 255 students from the University of Kyrenia (KU) answered the 25 questions (131, 51.4\%) 


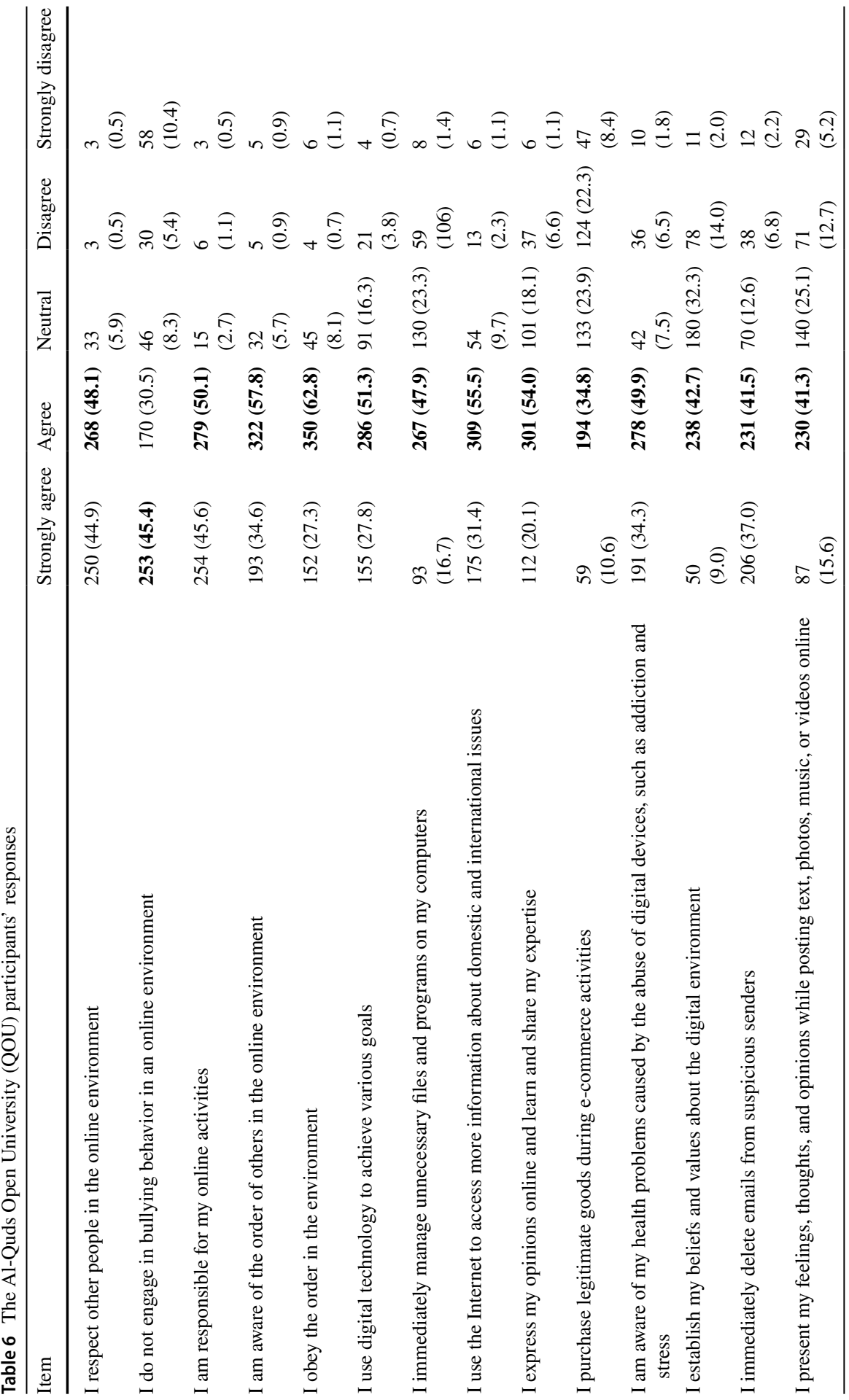




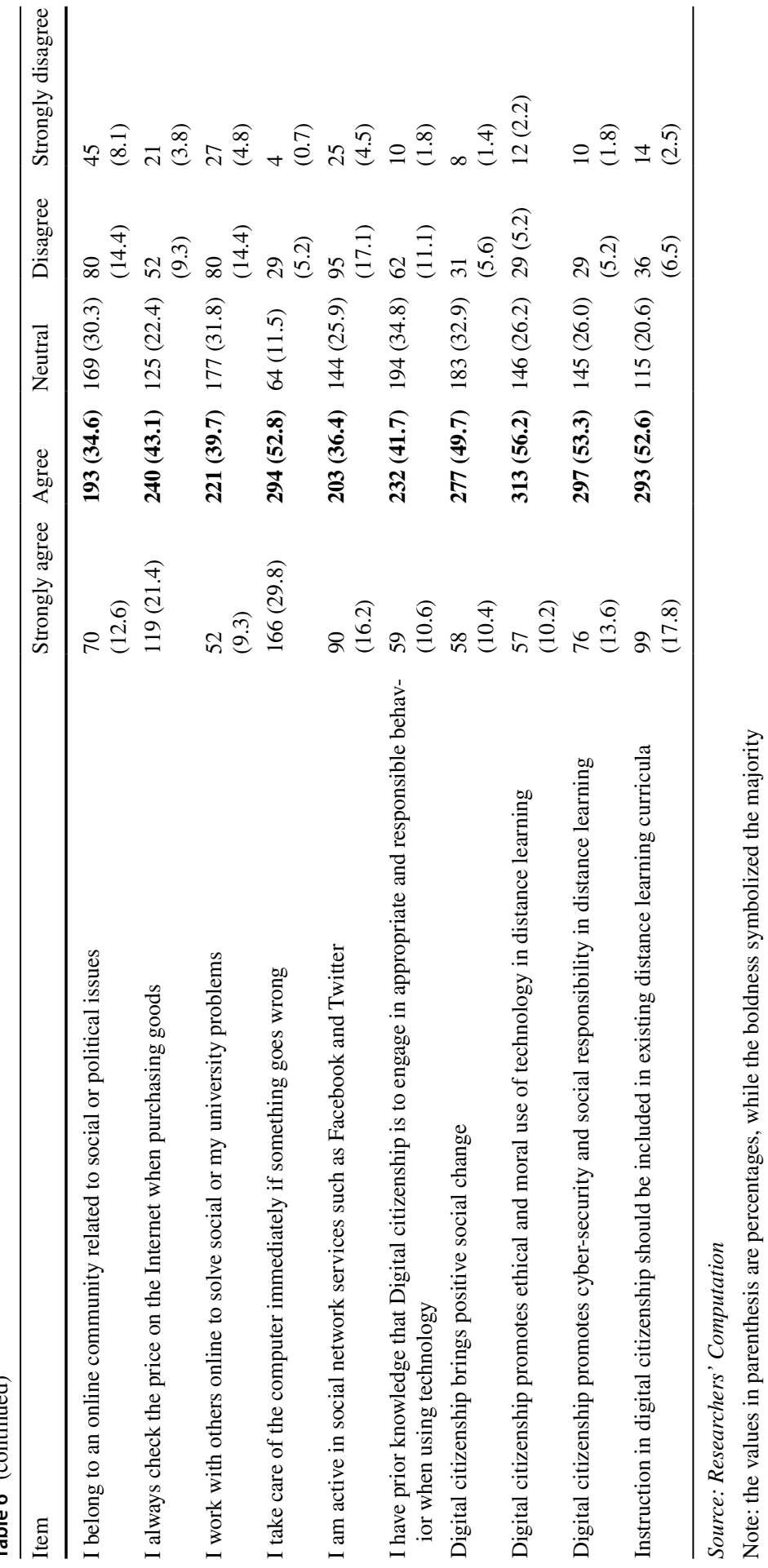




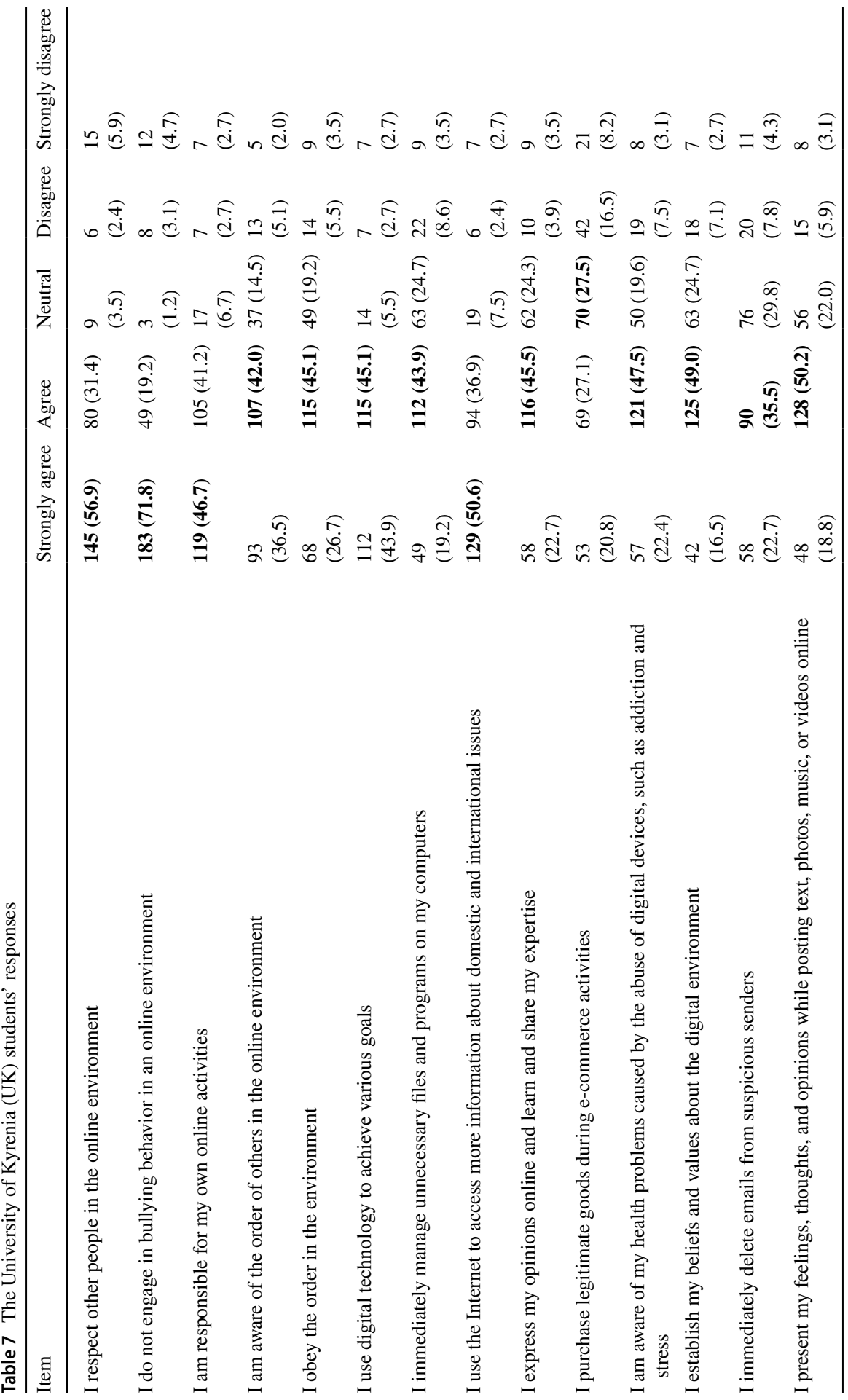




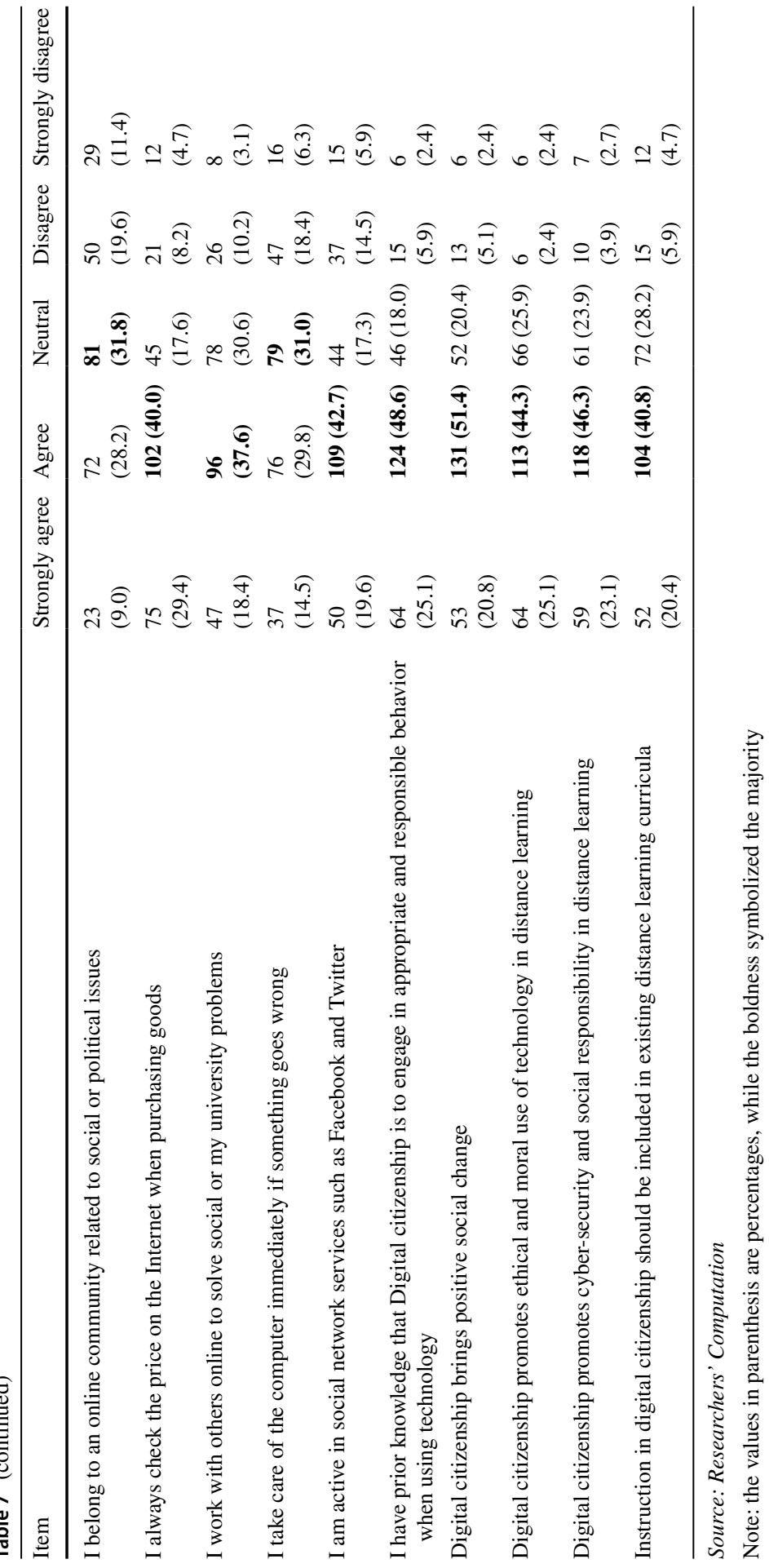


females and $(124,48.6 \%)$ males and thus approximately equal, the enrolled sample was varied in age groups $(208,81.6 \%)$ out of the participants from University of Kyrenia (KU) were between 18-22 years old, while $(19,7.5 \%)$ were more than 26 years old, the remaining of the sample $(28,11.0 \%)$ belonged to age group 23-25 years old. However, with respect to the study level of the sample, the majority of the respondents were in the first year of study $(241,94.5 \%)$ and $(8,3.1 \%)$ were in the second year of study. While only $(4,1.6 \%)$ and $(2,0.8 \%)$ were in the third and fourth year of study, respectively.

Table 6 shows the students response with respect to the 25 research questions where the values outside the brackets are the number of students in each case, the values in parenthesis are percentages/proportions, while the boldness symbolized the majority. From the table, majority of the students strongly agreed with that they do respect other people in the online environment; do not engage in bullying behavior in an online environment; responsible for their own online activities; and using the internet to access more information about domestic and international issues.

While on statements such as aware of the order of others in the online environment; obeying the order in the environment; using digital technology to achieve various goals; immediately manage unnecessary files and programs on their computers; expressing their opinions online and learn and share their expertise; purchasing legitimate goods during e-commerce activities; aware of my health problems caused by the abuse of digital devices such as addiction and stress; establishing their beliefs and values about the digital environment; immediately deleting emails from suspicious senders; presenting their feelings, thoughts, and opinions while posting text, photos, music, or videos online; always check the price on the Internet when purchasing goods; work with others online to solve social or my university problems; active in social network services such as Facebook and Twitter; having prior knowledge that digital citizenship is to engage in appropriate and responsible behavior when using technology; digital citizenship brings positive social change, digital citizenship promotes ethical and moral use of technology in distance learning, digital citizenship promotes cyber-security and social responsibility in distance learning, and instruction in digital citizenship should be included in existing distance learning curricula, the majority of the students do agreed with the statements.

But majority of the students are neutral with the statements on whether they purchase legitimate goods during e-commerce activities, belonging to an online community related to social or political issues, and taking care of the computer immediately if something goes wrong.

\subsection{Students awareness of digital citizenship}

This part presents the results of students' awareness of digital citizenship with respect to the questions including whether digital citizenship brings positive social change, digital citizenship promotes ethical and moral use of technology, students' awareness of their health, and students belonging to an online community related to social or political issues. 


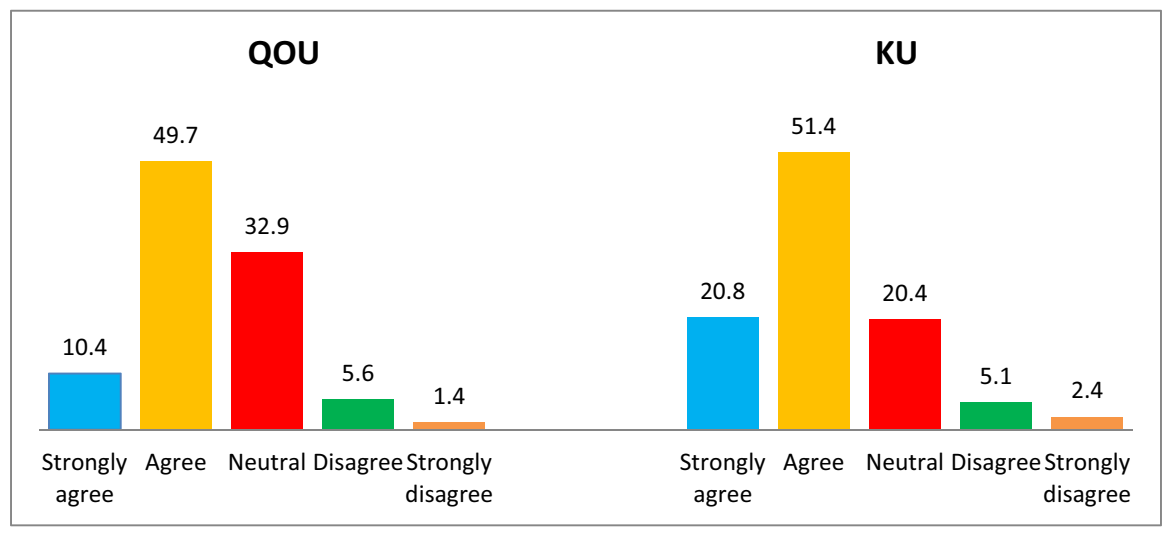

Fig. 1 Digital citizenship brings positive social change. Source: Researchers' Computation

Table 8 Z-test on whether digital citizenship brings positive social change

Students awareness with respect to whether digital citizenship brings positive social
change in QOU

Source: Researchers' Computation

The Asterisk * and ** denote significance at $1 \%$ and $5 \%$ levels, respectively

Figure 1 displays the results of whether digital citizenship brings positive social change. According to the figure, students from both higher academic institutions agreed that digital citizenship brings positive social change. The results are encouraging and indicate that students in the two higher academic institutions understand the issues that need to be tackled by adopting digital citizenship as part of the curriculum.

From Table 8, the results are encouraging. They indicate that students in QOU and $\mathrm{KU}$ understand that digital citizenship brings positive social change at 5\% and $1 \%$ levels, respectively. When comparing the level of awareness in the two higher institutions, the awareness of $\mathrm{KU}$ is greater than that of QOU at $1 \%$ level.

Figure 2 reports the results of the question of whether digital citizenship promotes ethical and moral use of technology in distance learning, the students from both universities are aware of the importance of this area. This indicates that even though that the students from both universities are skilled in technology use,their awareness may not inappropriate use of technology and for unethical ways such as cheating an assignment. This supports the important of integrating digital citizenship into distance education curriculum.

From Table 9, the results indicate that students from QOU and KU are aware of the importance of this area, which represents the student's awareness and recognition of the importance of digital citizenship in promoting ethical and moral 


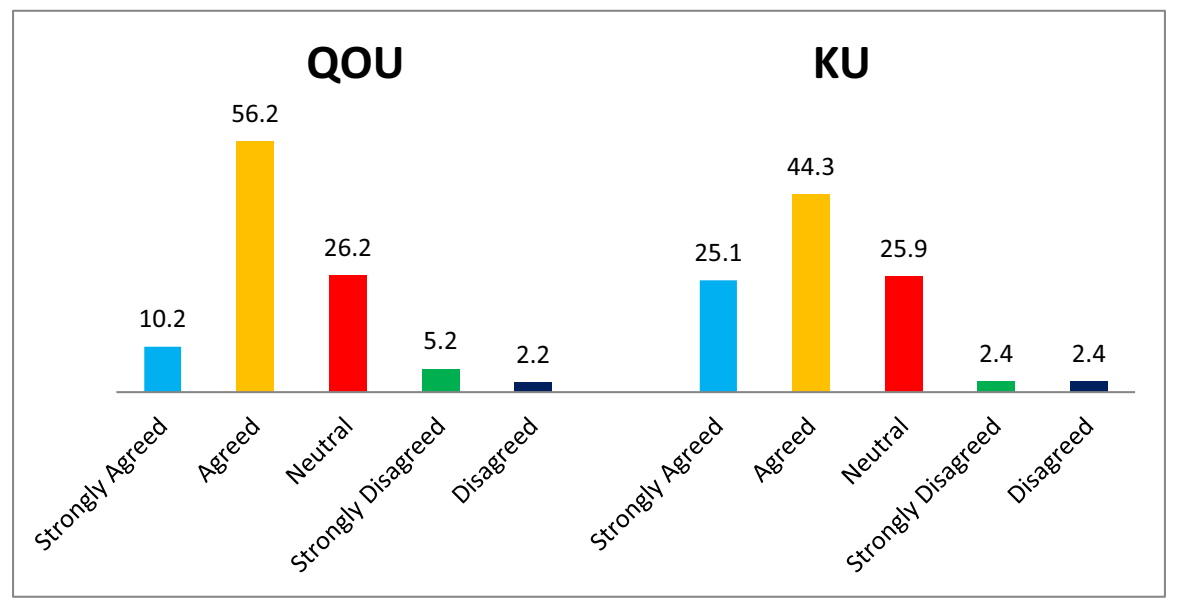

Fig. 2 Digital citizenship promotes ethical and moral use of technology. Source: Researcher's Computation

use of technology at $1 \%$ and $10 \%$ levels respectively, and when comparing the level of awareness in the two institutions, it can be observed that the awareness of $\mathrm{KU}$ is greater than that of QOU at $5 \%$ level.

Figure 3 portrays the results of whether the students are aware of their health problems caused by the abuse of digital devices, which means internet addiction, stress, and depression caused by the excessive use of technology that can be an issue affecting people's mental health. Overall results have shown that students from the two higher academic institutions are aware of the issues that might affect their health pertaining to the excessive use of technology. Results are comparable from the two institutions indicating a higher level of agreement that technology affects people's mental health. However, the student needs to learn how to avoid addiction, stress and depression by including this in the distance education curriculum.

From Table 10, the results indicate that students from QOU and KU are aware of the issues that might affect their health pertaining to the excessive use of technology both at $1 \%$ level and when compared from the two institutions, it is evidenced that the awareness of QOU is higher than that of KU.

Table 9 Z-test on whether digital citizenship promotes ethical and moral use of technology in distance learning

Students awareness with respect to whether digital citizenship promotes ethical and $Z$-score $=1.677 * * *$ moral use of technology in QOU

Students awareness with respect to whether digital citizenship promotes ethical and Z-score $=3.013^{*}$ moral use of technology in $\mathrm{KU}$

Comparing students awareness with respect to whether digital citizenship promotes Z Z-score $=2.201 * *$ ethical and moral use of technology between QOU and KU 


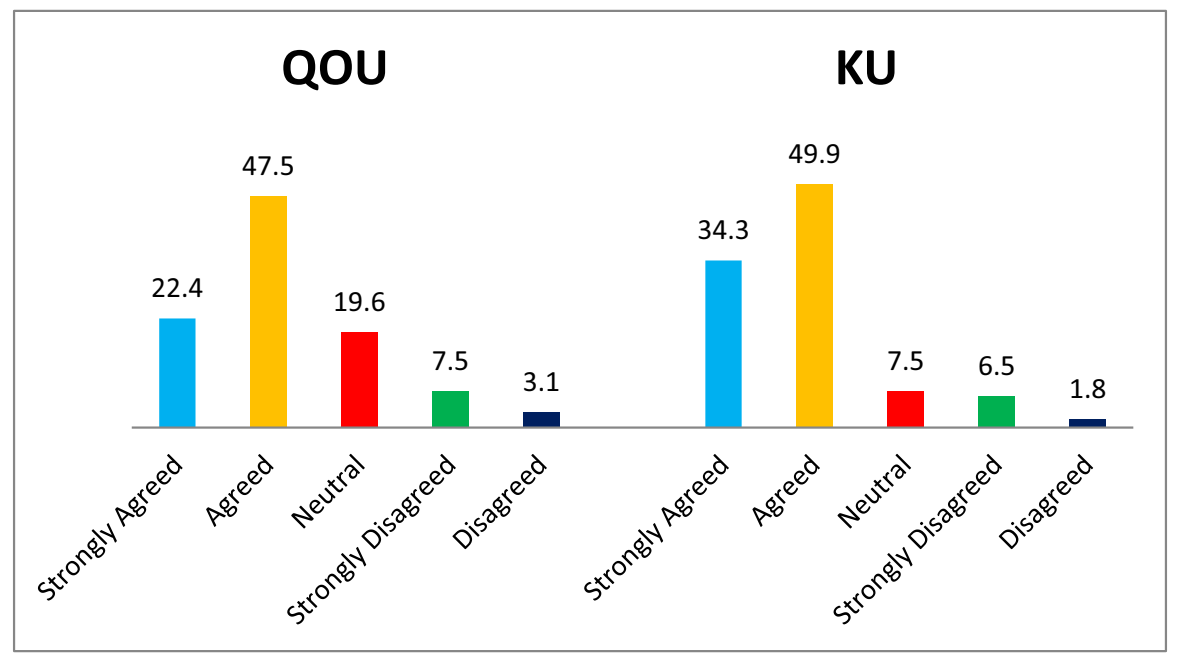

Fig. 3 Students awareness of their health. Source: Researcher's Computation

Table 10 Z-test on whether the students are aware of their health problems caused by the abuse of digital devices

Students awareness with respect to whether the students are aware of their health
problems caused by the abuse of digital devices in QOU
$\begin{aligned} & \text { Students awareness with respect to whether the students are aware of their health } \\ & \text { problems caused by the abuse of digital devices in KU }\end{aligned}$
$\begin{aligned} & \text { Comparing students awareness with respect to whether the students are aware of their } \\ & \text { health problems caused by the abuse of digital devices between QOU and KU }\end{aligned}$

Source: Researchers' Computation

The Asterisk * denotes significance at $1 \%$ level

Figure 4 displays the results of whether students belong to an online community related to social or political issues. This indicates that the majority of students from both institutions not belonging to online communities related to social or political issues, which may due to a lack of digital rights and law in both countries, where students should be able to use any type of technology and have the freedom to express themselves. So, student's participation in online communities and their behavior in cyberspace have an impact on others.

Table 11, shows that students from both institutions, QOU and KU do not belong to ceratin online communities related to social or political issues. This could be attributed to lack of digital rights and digital regulations, where students use of technology and the freedom to express themselves is rate at 5\% and $1 \%$ levels respectively. However, when comparing the level of awareness in the two institutions on whether students belong to an online community related to social or political issues, the awareness of QOU is greater than that of $\mathrm{KU}$ at $1 \%$ level.

Table 12 shows that students from QOU and KU are aware of digital citizenship in distance learning environment in terms of whether digital citizenship brings positive social changes, promoting ethical and moral use of technology, 


\section{QOU}

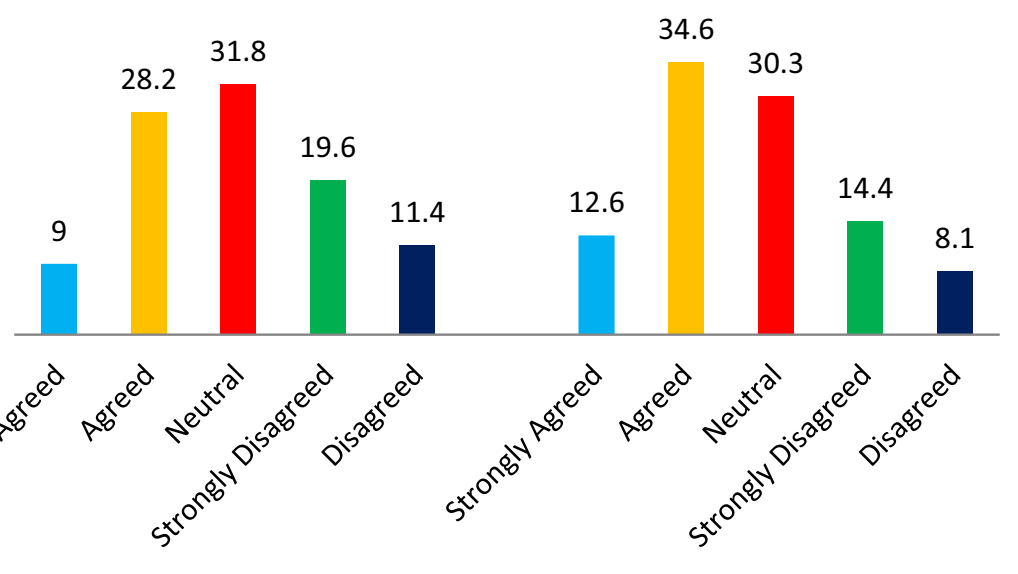

Fig. 4 Belonging to an online community related to social or political issues. Source: Researcher's Computation

Table 11 Z-test on whether students belong to an online community related to social or political issues

Students' awareness with respect to whether students belong to an online community Z-score $=2.872^{*}$ related to social or political issues in QOU

Students' awareness with respect to whether students belong to an online community Z Z-score $=1.993^{* *}$ related to social or political issues in $\mathrm{KU}$

Comparing students awareness with respect to whether students belong to an online Z Z-score $=6.491 *$ community related to social or political issues between QOU and KU

\section{Source: Researchers' Computation}

The Asterisk * and ** denote significance at $1 \%$ and $5 \%$ levels, respectively

Table 12 Z-test on students' level of awareness on digital citizenship in distance learning environment

Students' level of awareness on digital citizenship in distance learning environment (it sums all the sub-indices of students' level of awareness on digital citizenship in distance learning environment) in QOU

Students' level of awareness on digital citizenship in distance learning environment (it sums all the sub-indices of students' level of awareness on digital citizenship in distance learning environment) in $\mathrm{KU}$

Comparing students' level of awareness on digital citizenship in distance learning environments (it sums all the sub-indices of students' level of awareness on digital citizenship in distance learning environment) between QOU and KU

\section{Source: Researchers' Computation}

The Asterisk * denotes significance at $1 \%$ level

students' awareness of their health in excessive use of digital technology, and students not belonging to an online community related to social or political issues, which may be due to a lack of digital rights, digital security and law in both 


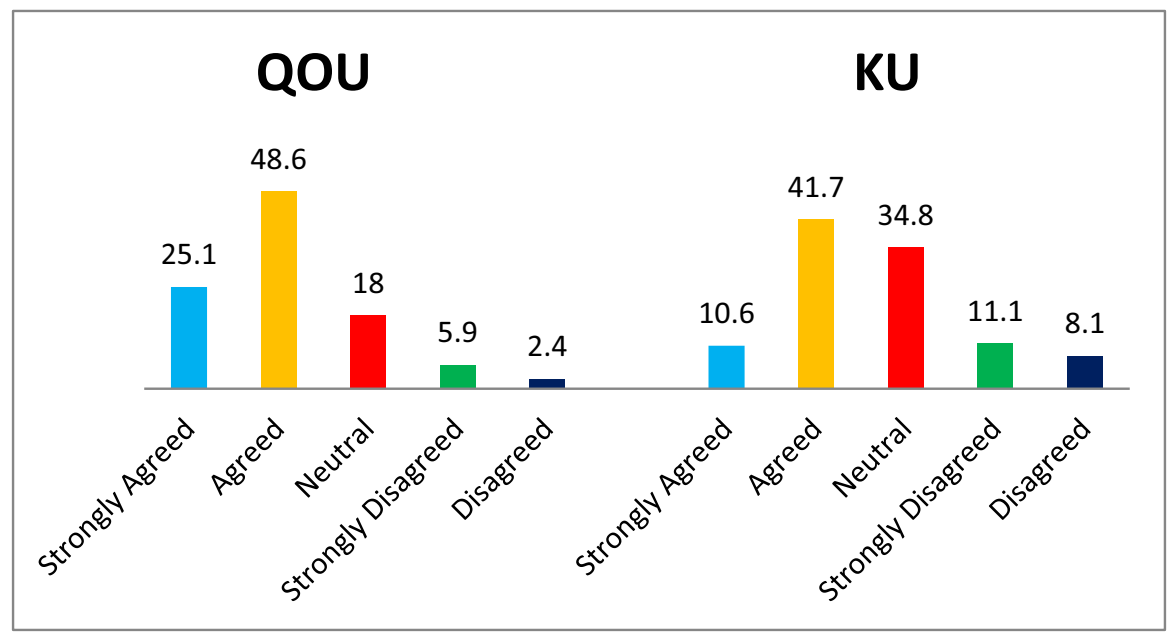

Fig. 5 Prior knowledge that digital citizenship is to engage in appropriate and responsible behavior when using technology. Source: Researcher's Computation

Table 13 Z-test on students' level of prior knowledge of digital citizenship in distance learning environment

Students' level of prior knowledge of digital citizenship in QOU

Z-score $=3.562 *$

Students' level of prior knowledge of digital citizenship in KU

$\mathrm{Z}$-score $=2.341 *$

Comparing students' level of prior knowledge of digital citizenship between QOU and Z-score $=7.668^{*}$ $\mathrm{KU}$

Source: Researchers' Computation

The Asterisk * denotes significance at $1 \%$ level

countries both at $1 \%$ level. However, when comparing the level of awareness in the two institutions, $\mathrm{KU}$ is greater than that of QOU at $1 \%$ level.

\subsection{Students knowledge of digital citizenship}

This part presents the results of students' knowledge of digital citizenship with respect to the questions including whether prior knowledge of digital citizenship, engage in bullying behaviour in an online environment, delete emails from suspicious senders, digital citizenship promotes cybersecurity and social responsibility. Starting with the results of whether prior knowledge of digital citizenship, the findings are presented in Fig. 5.

Figure 5 shows the results to the question about prior knowledge that digital citizenship is important in engaging in appropriate and responsible behavior using technology in both QOU and KU. The low strongly agree and higher disagree from AlQuds Open University (QOU) indicated that the student from University of Kyrenia (KU) has moreknowledge of the importance of digital citizenship. This may attributed to Palestine's lack of technical resources and poor internet access. In addition to the social norms and traditions that prevent women from participating in online activities. 


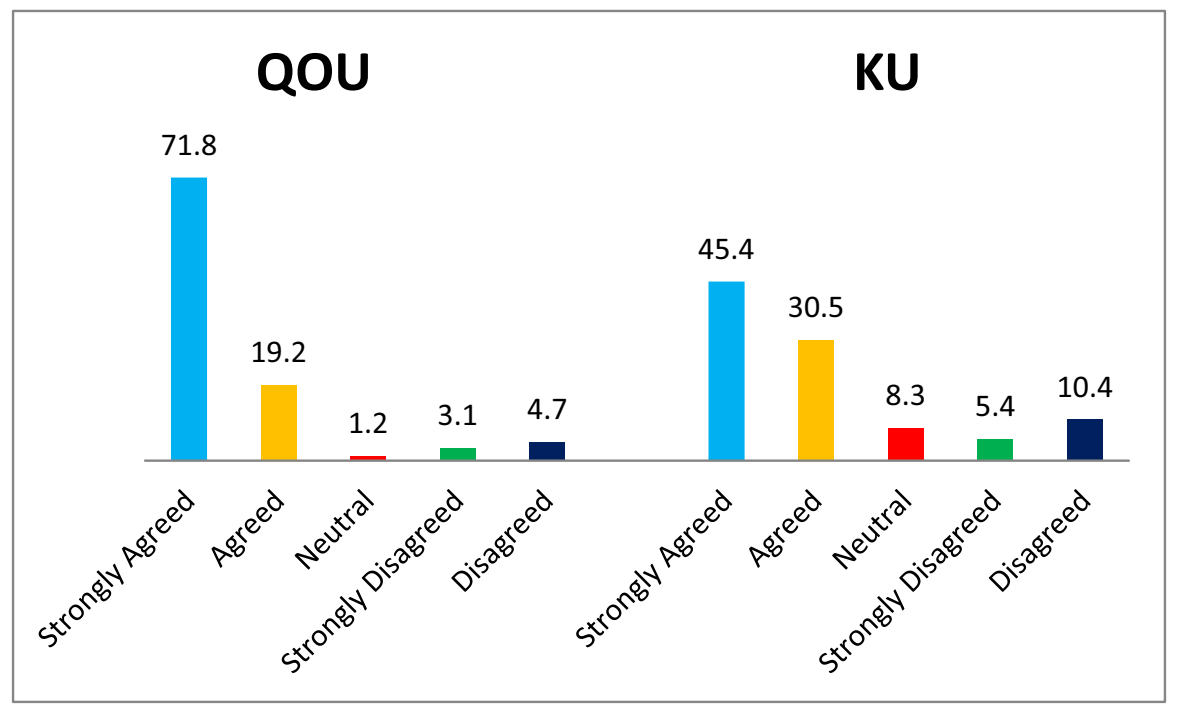

Fig. 6 Engage in bullying behaviour in an online environment. Source: Researcher's Computation

Table 14 Z-test on students' level of knowledge on engage in bullying behaviour in an online environment

Students' level of knowledge on engage in bullying behaviour in an online environ-
ment in QOU
$\begin{aligned} & \text { Students' level of knowledge on engage in bullying behaviour in an online environ- } \\ & \text { ment in KU }\end{aligned}$
$\begin{aligned} & \text { Comparing students' level of knowledge on engaging in bullying behaviour in an } \\ & \text { online environment between QOU and KU }\end{aligned}$

Source: Researchers' Computation

The Asterisk * and ** denote significance at $1 \%$ and $5 \%$ levels, respectively

Table 13 illustrates the results of Students' level of prior knowledge of digital citizenship in both QOU and KU. The responses presented in Fig. 5 indicate low strongly agree and higher disagree from QOU but high in KU. Therefore, the results in Table 13 can be read as students from QOU have less prior knowledge of digital citizenship at $1 \%$ level, which may be attributed to Palestine's lack of technical resources and poor internet access. In addition to the social norms and traditions that prevent women from participating in online activities. However, when comparing the level of knowledge in the two institutions, it can be observed that of $\mathrm{KU}$ is higher than that of QOU at $1 \%$ level.

Figure 6 reports the degree by which students view the importance of not participating in unacceptable activities in cyberspace such as bullying indicates their understanding of digital citizenship. On the question of not engaging in bullying activities in cyberspace, Fig. 6 shows the comparable results from the two universities. The big difference in percentage between the two universities is interesting. The high percentage $71.8 \%$ strongly agree at the University of Kyrenia 


\section{QOU}

\section{KU}

\section{5}

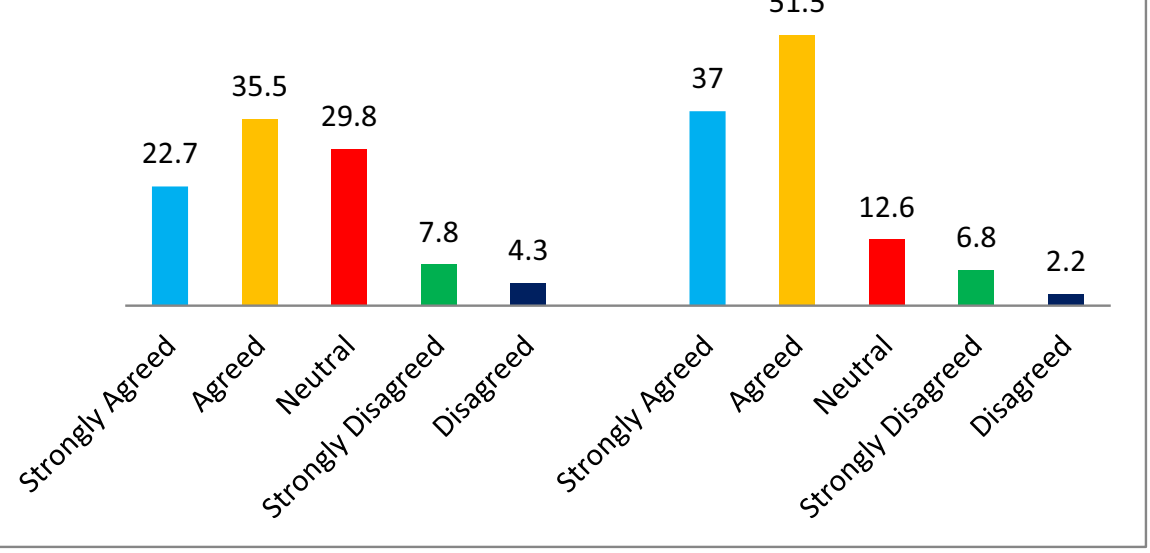

Fig. 7 Delete emails from suspicious senders. Source: Researcher's Computation

Table 15 Z-test on students' level of knowledge on deleting emails from suspicious senders in distance learning environment

Students' level of knowledge on deleting emails from suspicious senders in QOU

Z-score $=2.101 * *$

Students' level of knowledge on deleting emails from suspicious senders in KU

$\mathrm{Z}$-score $=1.693 * * *$

Comparing students' level of knowledge on deleting emails from suspicious senders

Z-score $=2.607 *$ between QOU and KU

Source: Researchers' Computation

The Asterisk *,**, and *** denote significance at $1 \%, 5 \%$, and $10 \%$ level, respectively

(KU) compared to $45.4 \%$ strongly agree at the Al-Quds Open University (QOU) indicates a deeper understanding of digital citizenship and its importance in dealing with such issues. Furthermore, this results support the result that KU students have a higher degree of digital citizenship knowledge.

Table 14 shows the results on the question of whether not engaging in bullying activities in cyberspace wherefrom the responses presented in Fig. 6, the degree by which students view the importance of not participating in unacceptable activities in cyberspace, such as bullying, indicates their understanding of digital citizenship in both QOU and KU, and this is statistical significance at $1 \%$ and $5 \%$ levels respectively. However, when comparing the level of knowledge in the two institutions, KU is greater than that of QOU at $1 \%$ level.

Student knowledge of dealing with potential problems such as spam and malicious email is also investigated. In dealing with suspicious emails, Fig. 7 shows the student's understanding of email fishing and what they need to do to avoid potential problems. The results show that Al-Quds Open University (QOU) students have a better understanding of the danger of fishing and malicious. This may be due to the fact that the majority of QOU respondents are older and females who treating with more responsibilities with these issues. 


\section{QOU}

\section{3}

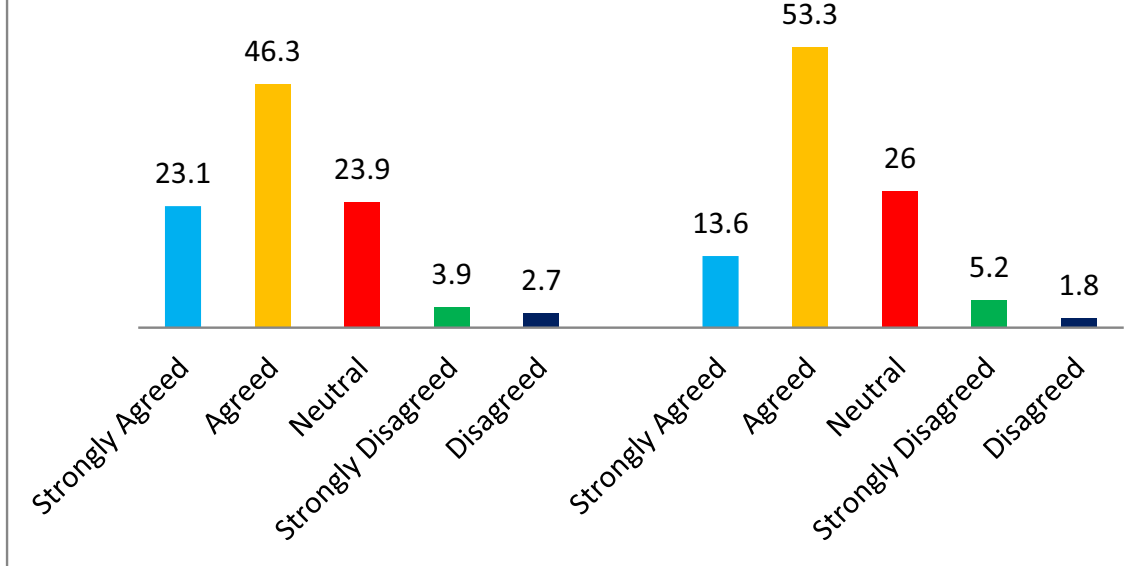

53.3

\section{KU}

Fig. 8 Digital citizenship promotes cybersecurity and social responsibility. Source: Researcher's Computation

Table 16 Z-test on students' level of knowledge on whether digital citizenship promotes cybersecurity and social responsibility in distance learning environment

\footnotetext{
Students' level of knowledge on whether digital citizenship promotes cybersecurity

Z-score $=2.734^{*}$ and social responsibility in QOU

Students' level of knowledge on whether digital citizenship promotes cybersecurity and social responsibility in $\mathrm{KU}$

Comparing students' knowledge level on whether digital citizenship promotes cyber- $\quad$ Z-score $=3.001 *$ security and social responsibility between QOU and KU
}

Source: Researchers' Computation

The Asterisk * denotes significance at $1 \%$ level

Table 15 shows the results on the question of whether students delete emails from suspicious senders. From the table, students of both QOU and KU understand the danger of fishing and malicious at 10\% and 5\% levels, respectively. This may be because most of the QOU students are elderly and females who are treating with more responsibilities with these issues. However, when comparing the level of knowledge in the two institutions, it can be deduced that the knowledge of KU is greater than that of QOU at $1 \%$ level.

A good citizenship is expected to promote better security practices to take a long the issue of cybersecurity and privacy in cyberspace and other important issues related to digital services. So, on whether digital citizenship promotes cybersecurity and social responsibility in distance education, Fig. 8 shows that student's understanding and knowledge of the value of digital citizenship. The results show a good understanding of students from both universities about the importance digital citizenship in promoting cyber security and social responsibility. 
Table 17 Z-test on students' level of knowledge on digital citizenship in distance learning environment

Students' level of knowledge on digital citizenship in distance learning environment (it sums all the sub-indices of students' level of knowledge on digital citizenship in distance learning environment) in QOU

Students' level of knowledge on digital citizenship in distance learning environment (it sums all the sub-indices of students' level of knowledge on digital citizenship in distance learning environment) in $\mathrm{KU}$

Comparing students' level of knowledge on digital citizenship in distance learning environments (it sums all the sub-indices of students' level of knowledge on digital citizenship in distance learning environment) between QOU and KU

Z-score $=3.012^{*}$

$\mathrm{Z}$-score $=2.823^{*}$

$\mathrm{Z}$-score $=4.773^{*}$

Source: Researchers' Computation

The Asterisk * denotes significance at $1 \%$ level

Table 16 shows the results on whether digital citizenship promotes cybersecurity and social responsibility in distance education. The results show a good understanding of students from both universities about the importance of digital citizenship in promoting cybersecurity and social responsibility, both at $1 \%$ level. However, when comparing the level of knowledge in the two institutions, it can be construed that the knowledge of KU is greater than that of QOU at $1 \%$ level.

Table 17 shows that students from KU and QOU have knowledge of digital citizenship in terms of prior knowledge of digital citizenship, engaging in bullying behaviour in an online environment, deleting emails from suspicious senders, and promoting cybersecurity and social responsibility both at $1 \%$ level. However, when comparing the level of knowledge in the two institutions, $\mathrm{KU}$ is greater than that of QOU at $1 \%$ level.

\subsection{Faculty awareness of digital citizenship}

\subsubsection{Importance of digital citizenship}

The study's findings revealed that most of the Al-Quds Open University's (QOU) interviewed faculty members believed that digital citizenship is very important; where one faculty member stated that it is only important in assessment and evaluation, seven faculty members agreed that it is important in increasing students' knowledge of internet use as well as their privacy and protection, two faculty members believe that it is important to improve students' behavior and skills in a digital environment, while one faculty member believes it is important to enhance social and cultural perspectives on technology as well as internet usage. The same finding was at the University of Kyrenia (KU), where all faculty members agreed that digital citizenship is important for distance learning students, four of them stating that it is important for effective education and helping students for better learning through distance learning, while some faculty members added that it is critical for proper information utilization, and contributes to enhancing the country's economy. 


\subsubsection{Students equipped to engage responsibly in digital citizenship}

Most faculty members from Al-Quds Open University (QOU) stated that the students are not equipped with digital citizenship and do not even know or be aware. On the other side, there was a difference in faculty members' responses from the University of Kyrenia (KU). Three of them stated that students are equipped with technological skills, while one states that it depends on the geographical and infrastructure of the area where the students live. Other faculty members also stated the students are well-equipped because they use information technology in distance learning. Four faculty members claimed that students were not equipped.

\subsubsection{The differences between students practice according to sex, age, and study level}

According to the study's results, five out of eight faculty members from Al-Quds Open University (QOU) agree that there is a difference in digital citizenship awareness due to sex, where they believed that females have more responsibility for using technology than males. All faculty members stated that there is a difference due to age, where they believe that the younger students have better knowledge of using technology, but older students are more responsible for using technology. However, two stated that there is no difference due to the study level, while the other two faculty members stated that there is a difference due to the study level. On the other hand, the study findings revealed that five faculty members from the University of Kyrenia (KU) believe that there are differences due to education but not due to sex and age. Other faculty members believe that there are differences due to sex, age, and education level.

The results for both universities showed an obvious difference between the two universities in terms of awareness of students and faculty members on digital citizenship in distance learning environment. When assessing the interview results, QOU faculty members had high awareness about digital citizenship as they are aware of the digital resources and tool, but KU has less awareness and needs to learn more about the available resources and tools.

\subsection{Faculty knowledge of digital citizenship}

The study's findings revealed that faculty members from the Al-Quds Open University (QOU) have differing perspectives about the definition of the digital citizenship concept. One faculty member defined student knowledge of Digital Citizenship based on their technical skills, three faculty members based on the students' digital resource ethics, and two faculty members based on the students' knowledge of cybercrime; however, one faculty member defined it based on student's engagement and contributions in a digital environment, while one faculty member defined it based on the student use of e-learning tools and resources. On the other hand, all 
faculty members at the University of Kyrenia (KU) defined the students' digital citizenship knowledge based on their computer skills.

\subsubsection{Teaching digital citizenship through distance learning}

According to the study results, three faculty members et al.-Quds Open University (QOU) suggested that distance learning should focus on teaching digital skills and behavior. One faculty member added digital etiquette to be considered, and another faculty member added teaching cybercrime. Moreover, another faculty member suggested that teaching methods include retrieving, analyzing, and evaluating the information. University of Kyrenia (KU) faculty members emphasized that we should focus on the skills needed for students to use technology more efficiently and ethically in the distance learning environment. Five of them suggested focusing on digital safety and ethics.

\subsubsection{Digital citizenship integration into the distance learning curriculum}

According to the study results, faculty members et al.-Quds Open University (QOU) believe integrating digital citizenship skills into distance learning curricula is important and necessary. Three of them stated that it could be integrated as part of the courses offered. Three faculty members indicated that it could be integrated by developing a specialized course for digital citizenship. Two faculty members indicated that integration can be done by adding a chapter in the essential courses. On the other hand, the Faculty members from Kyrenia University (KU) have stated that it is important and needed to integrate digital citizenship into the distance learning curriculum, and all of them agreed that a specialized digital citizenship course should be developed.

\subsubsection{Available resources and tools to incorporate in digital citizenship}

The study findings revealed that the faculty members et al.-Quds Open University (QOU) had proposed various tools and resources that can be used to enhance the student's digital citizenship skills in the distance learning environment. Most of them suggested tools such as Moodle, Zoom, and University TV Channel. Moreover, two faculty members added that the social media platforms WhatsApp and YouTube can be used for this purpose. On the other hand, the interview results with faculty at the University of Kyrenia (KU) reveal that three interviewed faculty members suggested distance learning applications and tools. Other faculty members suggested the available Digital Citizenship resources, such as the resources and materials created by the Global Digital Citizen Foundation. Two faculty members had no idea, while one faculty member stated that virtual classroom applications and digital content could be done. 


\subsubsection{Changes needed in curricula for digital citizenship}

The results of the interviews revealed that faculty members at the Al-Quds Open University (QOU) agreed on the importance of updating the distance learning curriculum to cultivate digital citizenship, whether by developing new courses or updating existing courses. Furthermore, some faculty members stated that the teaching methods should be revised or changed, and others suggested that they should have protocols, policies, and guidelines. On the other hand, the study's findings revealed that the faculty members at the University of Kyrenia (KU) share the same views about the need to update distance learning curricula; some faculty members suggested that government policies for digital citizenship in distance learning should be formulated and implemented, while others suggested that guidelines for digital citizenship in distance learning should be created to guide the students in the distance learning environment.

\section{Discussions}

The comparative study examined students' awareness and knowledge of digital citizenship at two different Universities in two different countries, namely the Al-Quds Open University (QU) in the Palestinian territories and the University of Kyrenia (KU) in the Turkish Republic of Northern Cyprus. The results revealed that students and faculty in both institutions were aware of digital citizenship in distance learning environment in terms of whether digital citizenship brings positive social changes, promoting ethical and moral use of technology, students' awareness of their health in excessive use of digital technology, and students not belonging to an online community related to social or political issues, but lacked the in-depth knowledge and understanding of concepts such as digital rights, digital security, and digital ethics. Furthermore, there was a clear difference between the two universities in terms of student and faculty awareness and knowledge of digital citizenship in a distant learning setting. When it came to the awareness and understanding of digital citizenship among the students of the two universities, it was discovered that KU students have a greater level of awareness and knowledge than QOU students. However, based on the interview results, QOU faculty members have a high level of awareness of digital citizenship since they are familiar with digital resources and tools, whereas KU faculty members have a lower level of awareness and need to learn more about the available resources and tools. Moreover, both faculty members from the two universities agreed on the relevance of digital citizenship in remote learning and agreed that digital citizenship should be integrated into the distance learning curriculum. The findings are in line with the study conducted by Al-Abdullatif and Gameil (2020) concerning the students' knowledge and their perception of digital citizenship in higher education, where they concluded that even though many of the students are aware of the concept of digital citizenship, there is still exist a wide gap in knowledge and practice regarding the security and the authenticity of digital information. This is also in line with the study conducted by Suson (2019) based on the awareness of teachers and students on the concept of digital citizenship. While students and faculty were aware of digital citizenship, the study revealed that they lacked 
knowledge in digital rights, digital security, and digital ethics. Faculty members and students at both universities expressed their digital citizenship knowledge by emphasizing the importance of digital citizenship in distance learning. The faculty members find digital citizenship important for students' privacy to enhance knowledge for effective distance learning. The students find it important for promoting ethical and moral use of technology in distance learning. This aligns with the technical innovation of Pedersen et al. (2018) that conducted workshops and training on the effectiveness of the hybrid model and concluded that the model was successful in strengthening the gaps that were part of the digital citizenship and distance learning platform.

\section{Concluding remarks}

The this study conducted a comparative study between two different higher academic institutions, namely Al-Quds Open University (QOU) in Palestine and The University of Kyrenia (KU) in the Turkish Republic of Northern Cyprus in year 2020 where the selected universities used distance learning technologies to deliver learning courses. The survey constituted 828 participants, of which 565 from QOU and 263 from KU. The techniques employed include interview, descriptive analysis, and Z-test technique.

- The results revealed that students and faculty in both institutions were aware of digital citizenship in distance learning environment in terms of whether digital citizenship brings positive social changes, promoting ethical and moral use of technology, students' awareness of their health in excessive use of digital technology, and students not belonging to an online community related to social or political issues, but lacked the in-depth knowledge and understanding of concepts such as digital rights, digital security, and digital ethics.

- The results for both universities showed an obvious difference between the two universities in terms of awareness and knowledge of students and faculty members on digital citizenship in distance learning environment. With respect to the difference in awareness and knowledge of digital citizenship among the students of the institutions, it found that the awareness and knowledge of digital citizenship among KU students are higher than QOU students. However, with respect to the difference in awareness and knowledge of digital citizenship among the faculty members of the institutions based on the interview results, QOU faculty members had high awareness about digital citizenship as they are aware of the digital resources and tool, but KU has less awareness and needs to learn more about the available resources and tools.

- Moreover, both faculty members at the two different universities agreed on the importance of digital citizenship in distance learning and agreed that there is a need to integrated digital citizenship into the distance learning curriculum.

The implication of the finding of this paper is that the level of students and faculty awareness and knowledge on digital citizenship in the distance learning environment gathered and interpreted in this paper could help other organizations 
around the world integrate digital citizenship in the distance learning curricula. Suppose students are to take on the responsibilities of digital citizenship. In that case, educational institutions must incorporate digital citizenship as an integral component of the distance learning program and be prepared to overcome challenges to students taking on these responsibilities. The findings of this research could be valuable in guiding universities and faculty aimed at incorporating digital citizenship into distance learning by improving the teaching methods, updating and developing new courses. In addition, it could be crucial to the educational policy reform for developing guidelines, protocols, and policies for cultivating digital citizenship in the distance learning environment.

Acknowledgements We thank almighty God for giving us the strength to start and complete this paper.

Data availability The data used and materials are available on request.

\section{Declarations}

Ethical approval This article involves human participants and all procedures performed in studies involving human participants were in accordance with the ethical standards of the institutional and/or national research committee and with the 1964 Helsinki declaration and its later amendments or comparable ethical standards.

Conflict of interest We the authors, declared that we have no conflict of interest.

\section{References}

Al-Abdullatif, A., \& Gameil, A. (2020). Exploring students' knowledge and practice of digital citizenship in higher education. International Journal of Emerging Technologies in Learning, 15(19), 122-142. https://www.learntechlib.org/p/217915.

Almarashdeh, I. \& Alsmadi, M. (2016). Investigating the acceptance of technology in distance learning program. 2016 International Conference on Information Science and Communications Technologies (ICISCT), 1-5. https://doi.org/10.1109/ICISCT.2016.7777404

Ata, R., \& Yıldırım, K. (2019). Turkish Pre-service Teachers' Perceptions of Digital Citizenship in Education Programs. Journal of Information Technology Education: Research, 18, 419-436. https://doi.org/ $10.28945 / 4392$

Choi, M., Glassman, M., \& Cristol, D. (2017). What it means to be a citizen in the internet age: Development of a reliable and valid digital citizenship scale. Computers \& Education, 107, 100-112. https://doi.org/ 10.1016/j.compedu.2017.01.002

Clough, H., \& Closier, A. (2018). Walking the talk: Using digital media to develop distance learners' digital citizenship at the Open University (UK). The Reference Librarian, 59(3), 129-133. https://doi.org/10. 1080/02763877.2018.1468848

Common Sense Media White Paper. (2011). Digital Literacy and Citizenship in the 21st Century: Educating, Empowering and Protecting America's Kids. Retrieved from http://www.commonsensemedia.org/ sites/default/files/DigitalLiteracyandCitizenshipWhitePaper-Mar2011.pdf05.04.2013. Accessed 12 Aug 2020.

Elmali, F., Tekin, A., \& Polat, E. (2020). A Study on digital citizenship: Preschool teacher candidates vs. computer education and instructional technology teacher candidates. Turkish Online Journal of Distance Education, 21, 251-269. https://doi.org/10.17718/tojde.803423

Fields, A., \& Hartnett, M. (2018). Digital fluency in open, flexible and distance learning. Journal of Open, Flexible, and Distance Learning, 22(1), 1-5. https://www.learntechlib.org/p/184658.

Grammon, T.A. (2020). Comparing digital citizenship perceptions of online students and teachers. A dissertation presented in partial fulfilment of the requirements for the degree doctor of education. Liberty University, Lynchburg, VA. https://digitalcommons.liberty.edu/doctoral/2756. Accessed 4 March 2021. 
Isman, A., \& Gungoren, O. C. (2014). Digital citizenship. The Turkish Online Journal of Educational Technology, 13(1), 73-77. http://tojet.net/articles/v13i1/1317.pdf.

Jwaifell, M., \& Alkhales, B. M. (2019). The proper use of technologies as a digital citizenship indicator: A comparative study of two Universities in the Middle East. Journal of Studies in Education, 9, 1-16. https://doi.org/10.5296/jse.v9i1.14079

Maftuhin, Azis, A. \& Nugraha, D.M. (2021). Implementation of Digital Citizenship's Concept in Online Learning of Civic Education. Advances in Social Science, Education and Humanities Research, volume 524. 1-8. Proceedings of the 1st International Conference on Character Education. https://poshu kach.com/redir?user_type $=4 \mathrm{f} \&$ type $=$ sr\&redir $=$ eJzLKCkpKLbS1y8vL9dLLMlJzCvJLNYtKEotLtZL zs_VTywqyUzOSdU3NDK1NDUyNrLQK0hJY2AwNDM2NjK0NDQyZGiad8t_71Lx-cbF3LF29bc jAHZ9G0E\&src=8d4b06\&via_page=1. Accessed 1 Oct 2021.

Manasco, C. (2020). Digital citizenship and distance learning. https://learnsafe.com/digital-citizenship-anddistance-learning/. Accessed 1 Oct 2021.

Martin, F., Hunt, B., Wang, C., \& Brooks, E. (2020). Middle school student perception of technology use and digital citizenship practices. Computers in the Schools, 37(3), 196-215. https://doi.org/10.1080/07380 569.2020.1795500

Pedersen, A. Y., Nørgaard, R. T., \& Köppe, C. (2018). Patterns of inclusion: Fostering digital citizenship through hybrid education. Journal of Educational Technology \& Society, 21(1), 225-236. http://www. jstor.org/stable/26273882.

Ribble, M., \& Bailey, G. (2007). Digital citizenship in schools. ISTE. https://www.amazon.com/Digital-Citiz enship-Schools-Mike-Ribble/dp/1564842320. Accessed 12 March 2020.

Ribble, M. (2008). Passport to digital citizenship: Journey toward appropriate technology use at school and at home. http://www.iste.org/learn/publications/learning-leading/issues/december-january-2008-2009/ passport-to-digital-citizenship05.04.2013. Accessed 12 March 2020.

Snyder, S. (2016). Teachers' perceptions of digital citizenship development in middle school students using social media and global collaborative projects. https://scholarworks.waldenu.edu/dissertations/2504. Accessed 18 March 2020.

Strauss, A., \& Corbin, J. (1990). Basics of qualitative research. Sage Publications. https://www.worldcat. org/title/basics-of-qualitative-research-grounded-theory-procedures-and-techniques/oclc/21763197. Accessed 13 March 2020.

Suson, R. L. (2019). Appropriating digital citizenship in the context of basic education. International Journal of Education, Learning and Development, 7(4), 44-66. https://www.eajournals.org/wp-content/uploa ds/Appropriating-Digital-Citizenship-in-the-Context-of-Basic-Education-1.pdf.

UNESCO. (2020). Distance learning strategies in response to COVID - 19 school closures. https://unesdoc. unesco.org/. Accessed 13 May 2021.

Xu, S., Yang, H. H., MacLeod, J., \& Zhu, S. (2019). Social media competence and digital citizenship among college students. Convergence, 25(4), 735-752. https://doi.org/10.1177/1354856517751390

Zook, C. (2019). What is digital citizenship \& how do you teach it? https://www.aeseducation.com/blog/ what-is-digital-citizenship. Accessed 14 May 2021.

Publisher's note Springer Nature remains neutral with regard to jurisdictional claims in published maps and institutional affiliations. 